\title{
A global soil and sediment transfers database for the Anthropocene
}

\author{
Veerle Vanacker ${ }^{1}$ and Thomas Hoffmann ${ }^{2}$ \\ 2nd GloSS Workshop, Louvain-la-Neuve, Belgium, 30 January - 1 February 2017
}

Anthropogenic soil erosion causes soil degradation, reduces soil productivity (Fig. 1), compromises freshwater ecosystem services and drives geomorphic and ecological change in rivers and their floodplains (Anthony et al. 2014; Wang et al. 2016). Despite our knowledge of the fundamental mechanistic processes of soil erosion, transport and deposition and the control of climate, soil erodibility, topography, and land use and management on soil and sediment transfers, the rich variety of past land use and human settlement patterns worldwide implies that global patterns of anthropogenic soil erosion and fluvial sediment transfer remain poorly understood (Vanacker et al. 2014).

We need better global assessments of anthropogenic soil erosion and the consequent transfer and storage of sediment to the coastal zones to reduce the societal impact of human-accelerated erosion. The PAGES Global Soil and Sediment transfers in the Anthropocene (GloSS) working group aims to build a comprehensive global database on soil and sediment transfers in the Anthropocene, to identify hotspots of soil erosion and sediment deposition in response to human impacts, and locate data-poor regions as strategic foci for future work. To achieve this aim, 39 participants from 15 countries with expertise in soil erosion assessments, erosion modeling, humanlandscape interactions and global sediment fluxes attended the meeting.

The first part of the meeting was dedicated to oral and poster presentations, including 11 keynotes and smaller topical presentations on anthropogenic sediment fluxes, humanclimate interaction on river systems and sediment fluxes, and temporal changes in sediment budgets for lakes and floodplains from various regions of the world. Major focus was given to the coverage of GloSS-related studies on each continent and regarding the various environments considered for the GloSS database (i.e. hillslope, river channels, floodplains, lakes and deltas). The second part of the workshop was entirely dedicated to breakout group discussions, where the workshop participants revised the GloSS database structure and discussed standard operating procedures for data-submission and internal procedures for server-side data cleaning and quality control. Participants agreed that the GloSS database should focus on a limited number of proxies/indices that are widely available: (1) sediment loads (e.g.



Figure 1: Overgrazing reducing infiltration and accelerating runoff and soil erosion in the Northern Andes. Gully systems and landslides are the major contributors of sediment to the fluvial system. Credit: Veerle Vanacker, July 2013

Syvitski and Kettner 2011), (2) sedimentation rates (Yang and Lu 2014), (3) cosmogenic radionuclide denudation rates (e.g. Portenga and Bierman 2011), and (4) erosion rates (e.g. Maetens et al. 2012). For each of the four proxies/indices, a breakout group revised and improved the metadata structure, and defined parameters or variables that need to be included, their format, unit of measurement, quality control, and spatial and temporal integration. Group members reviewed the criteria, which have now been included in a comprehensive data dictionary.

The group also updated the GloSS roadmap for two primary products to be completed before the end of the project in 2017. Based on the GloSS database, we plan to produce a global overview map of the availability of proxies and indices to quantify soil and sediment transfers throughout the Holocene. The group also discussed how to take advantage of the expertise gained from highly detailed case studies worldwide, and proposed to work towards a review paper on erosion and sedimentation issues in the Anthropocene to increase awareness on the topic.

The GloSS working group held a brief gathering in May 2017, during the 5th PAGES
OSM meeting in Zaragoza, Spain, to discuss progress. More information is available on the PAGES website.

The workshop was co-organized by the Université catholique de Louvain, University of Leuven and Université de Liège, Belgium. Funding was provided by PAGES and the Belgian Fonds de la Recherche Scientifique (FNRS).

\section{AFFILIATIONS}

'Earth and Life Institute, Université Catholique de Louvain, Louvain-la-Neuve, Belgium

${ }^{2}$ German Federal Institute of Hydrology, Koblenz, Germany

\section{CONTACT}

Veerle Vanacker: Veerle.vanacker@uclouvain.be REFERENCES

Anthony EJ et al. (2014) Earth Sci Rev 139: 336-361 Maetens W et al. (2012) Prog Phys Geogr 36: 599-563 Portenga EW, Bierman PR (2011) GSA Today 21: 4-10 Syvitski JPM, Kettner A (2011) Phil trans R Soc A 369: 957-975

Vanacker V et al. (2014) Landsc Ecol 29: 293-309

Wang S et al. (2016) Nat Geosci 9: 38-41

Yang X, Lu XX (2014) Geom 227: 49-59 